\title{
Invasive Group A Streptococcal Infection and Vaccine Implications, Auckland, New Zealand
}

\author{
Atheer Safar, Diana Lennon, Joanna Stewart, Adrian Trenholme, Dragana Drinkovic, Briar Peat, \\ Susan Taylor, Kerry Read, Sally Roberts, and Lesley Voss
}

\begin{abstract}
We aimed to assess the effect of invasive group $A$ streptococcal (GAS) infection and the potential effects of a multivalent GAS vaccine in New Zealand. During January 2005-December 2006, we conducted prospective population-based laboratory surveillance of Auckland residents admitted to all public hospitals with isolation of GAS from normally sterile sites. Using emm typing, we identified 225 persons with confirmed invasive GAS infection (median 53 years of age; range 0-97 years). Overall incidence was 8.1 cases per 100,00 persons per year $(20.4 / 100,000 /$ year for Maori and Pacific Islanders; 24.4/100,000/year for persons $\geq 65$ years of age; 33/100,000/year for infants $<1$ year of age). Nearly half (49\%) of all cases occurred in Auckland's lowest socioeconomic quintile. Twenty-two persons died, for an overall case-fatality rate of $10 \%$ (63\% for toxic shock syndrome). Seventy-four percent of patients who died had an underlying condition. To the population in our study, the proposed 26-valent vaccine would provide limited benefit.
\end{abstract}

$\mathrm{D}$ uring the 2 decades since recognition of streptococcal toxic shock syndrome (STSS), there have been many publications on invasive group A streptococcal (GAS) infections, some population-based (1-4). The spectrum

Author affiliations: Auckland City Hospital, Auckland, New Zealand (A. Safar, S. Roberts); The University of Auckland, Auckland (D. Lennon, J. Stewart); Kidz First Children's Hospital/Middlemore Hospital, Auckland (A. Trenholme); North Shore Hospital, Auckland (D. Drinkovic, K. Read); The University of Auckland/Middlemore Hospital, Auckland (B. Peat); Middlemore Hospital, Auckland (S. Taylor); and Starship Children's Hospital, Auckland (L. Voss)

DOI: 10.3201/eid1706.100804 of infection caused by Streptococcus pyogenes varies widely from invasive disease, such as bacteremia, sepsis, necrotizing fasciitis (NF), and STSS, to noninvasive infection, most commonly pharyngitis with suppurative complications, such as otitis media, and nonsuppurative complications, such as acute rheumatic fever (ARF) and acute glomerulonephritis (APSGN).

GAS infection causes a substantial number of illnesses and deaths, especially in the developing world, with $\approx 500,000$ deaths worldwide annually, attributable mostly to $\mathrm{ARF}$ and its sequelae, rheumatic heart disease, and invasive infection (5). GAS disease and its sequelae, including GAS pharyngitis, have been well documented in New Zealand (6-12; http://dnmeds.otago.ac.nz/departments/womens/ paediatrics/research/nzpsu/pdf/2008_report.pdf).

With renewed interest in GAS vaccines (13), understanding the complete spectrum of disease, including invasive GAS disease, in diverse populations is essential. The vaccine most completely studied is a 26 -valent vaccine based on emm types and $M$ subtypes collected across GAS diseases from the United States (14). We previously published a population-based approach of laboratory surveillance for invasive bacterial diseases in Auckland's public hospitals where all persons with acute disease would be admitted (8,15-18). Using this approach, we demonstrate the effects of invasive GAS on the Auckland population to complement our knowledge of other GAS-associated diseases by using prospectively collected incidence data, clinical characteristics, associated underlying conditions, and the associated emm types. This study also provided an opportunity to establish the direction of further investigations and to focus interventions in New Zealand. 


\section{Methods}

\section{Surveillance}

We enrolled patients during January 1, 2005December 31, 2006. Patients were included if they resided in metropolitan Auckland and had a GAS isolate cultured from a previously sterile body cavity. Patients with STSS were included in accordance with the consensus definition (19); STSS also was the diagnosis for patients who were dead on arrival or who died within 48 hours after illness onset and for whom laboratory data were insufficient in accordance with the methodology of Davies et al. (1). NF was defined as tissue necrosis diagnosed by histopathologic examination or by the treating surgeon during surgical debridement. Patients could have had $>1$ diagnosis, with the exception of bacteremia without a source. Clinical syndromes, such as skin or soft tissue infection, had to be accompanied by recovery of an isolate from a normally sterile site or specimen, such as blood, to meet the case definition. Nosocomial infection was defined as GAS infection in patients who had been hospitalized for $>72$ hours. Invasive GAS infection was defined as postpartum if it occurred in a woman who was pregnant or $\leq 30$ days after delivery or who had clinician-defined puerperal fever, chorioamnionitis, or a septic abortion. Women from whom GAS was isolated from amniotic fluid or placenta alone were excluded (20). Our study was approved by the regional ethics committee and each hospital's research committee and Maori research committee.

Data were collected from the microbiology laboratories serving all 3 Auckland regional District Health Board (DHB) hospitals, i.e., Auckland City Hospital and Starship Children's Hospital (Auckland DHB); Middlemore Hospital, which includes Kidz First Children's Hospital (Counties Manukau DHB); and North Shore Hospital and Waitakere Hospital (Waitemata DHB). All Auckland residents with serious medical illness would attend 1 of these hospitals.

Auckland (2006 population: 1,387,780), New Zealand's largest city, comprises one third of the country's population and is the country's most ethnically diverse city. In 2006, 19.0\% of residents self-identified as Asian, $14.4 \%$ as Pacific Islander, $11.1 \%$ as indigenous Maori, and $56.5 \%$ as European. The climate is temperate, with summer occurring during December through March. We used New Zealand birth data for infants $<1$ year of age and customized New Zealand census charts for DHBs as denominators.

We obtained demographic and clinical features by reviewing medical charts and electronic documents. To ensure complete surveillance, we requested International Classification of Diseases, 10th Revision, diagnoses from DHB data managers. We contacted the regional coroner and forensic pathologist to seek out records of deaths (including deaths in the community) caused by GAS infection and scrutinized intensive care unit (ICU) data for diagnoses of shock from GAS, STSS, or NF. Disease severity was determined by length of stay, ICU admission, and use of surgical and medical procedures.

We assigned each invasive GAS infection in the Auckland region a deprivation score by using the New Zealand Deprivation Index 2006 (www.moh.govt.nz). This index measures socioeconomic status (SES) in small areas according to 9 variables (income, income assistance, education, access to a car and phone, household crowding, employment, single-parent family, housing rented or owned).

\section{Laboratory Techniques}

$\beta$-hemolytic colonies on blood agar were typed as Lancefield group A by using commercially available latex agglutination kits (Pro-Lab Diagnostics, Austin, TX, USA). Group A isolates were sent to Environmental Science and Research Laboratory (Wellington, New Zealand) for emm typing by using established procedures (21). Concordance between emm types and $\mathrm{M}$ serotypes has been established (21). Antimicrobial drug sensitivities were determined by routine methods (22).

\section{Estimates of Vaccine Benefit}

We used emm typing to estimate the proportion of cases and deaths caused by emm types in the proposed 26-valent vaccine. These emm GAS types are 1, 2, 3, 5, 6, $11,12,13,14,18,19,22,24,28,29,33,43,59,75,76,77$, $89,92,94,101$, and 114 (14). We then calculated potential vaccine efficacy in the most at-risk Auckland populations: persons $<5$ years of age and $\geq 65$ years of age.

\section{Results}

\section{Epidemiology}

During the 24-month study period, we identified 333 patients who potentially had invasive GAS infections. Of these, we excluded 118 who did not fulfill the inclusion criteria. The most common reasons for exclusion were isolation from a nonsterile site or residence outside metropolitan Auckland at the time of diagnosis. Using the electronic discharge summaries based on International Classification of Diseases, 10th Revision, coding, we identified and included 10 (4\%) additional cases that fit the case definition.

The 225 patients were from all ethnic groups: European (77 [34\%] patients), Maori (69 [31\%]), Pacific Islanders (70 [31\%]), and other ethnicities (7 [3\%]). For 2 patients, no information was available about ethnicity. For the 225 patients, median age was 53 years (range 0-97 years), and 119 (53\%) patients were male. Ethnic disparities, although 
notable in the extremes of life, did not differ significantly by age (Figure 1; Table 1). The 198 patients with invasive GAS infection for whom SES information was available were more likely to originate in areas designated by the New Zealand Deprivation Index 2006 as lower SES areas than in higher SES areas (Table 2). Forty-nine percent of case-patients were from the lowest SES quintile.

\section{Case-Fatality Rate}

Twenty-two patients died, for an overall case-fatality rate (CFR) of 10\% (Figure 1, Table 3). Fourteen of these patients died within 72 hours after hospital admission. Three infants (one 2 months of age and two 4 months of age) who died in the community had STSS. One death previously had been attributed to sudden infant death syndrome.

The median age of patients who died was 62 years (range 2 months -86 years). Eighteen adults who died had multiple concurrent illnesses. The highest CFR (31\%) was for infants (a total of 4 deaths in three 4-month-old infants and one 2-month-old infant); these were the only deaths among children $<15$ years of age.

All infants who died had GAS-positive blood cultures. One who died in the community also had GAS-positive cerebrospinal fluid. Three of the 4 deaths occurred in the community and are attributed to STSS. The illness of the fourth (hospitalized) infant also met the criteria for STSS. Bronchopneumonia was found at post-mortem examination in 2 infants ( 1 hospitalized, 1 in the community). Two of the infants who died in the community had additional pathogens isolated from postmortem blood cultures (Staphylococcus aureus in both cases and Streptococcus pneumoniae and viridans streptococci in 1 each) but no gram-negative organisms.

\section{Clinical Features}

The most common clinical feature was skin and soft tissue infection $(97 / 225 ; 43 \%$ ) (Table 3$)$. Of the 30 patients with STSS, $26(87 \%)$ had an underlying condition before the onset of acute GAS disease. Median age at STSS occurrence was 57 years (range 2 months-86 years). Six cases occurred in children $<5$ years of age. Empyema ( 4 cases; $p<0.0001$ ) and brain abscess ( 2 cases; $p=0.0011$ ) occurred more frequently in children $\leq 14$ years of age than in adults. The incidence of bacteremia with no focus of infection was 1.4 cases per 100,000 persons per year overall, but 3.7 per 100,000 for children $<5$ years of age $(n=7)$.

Seven cases of GAS postpartum infection were recorded for women 15-49 years of age, for a rate of 0.16 cases per 1,000 live-born infants (Maori and Pacific Islander, 0.21 cases $/ 1,000$ live-born infants). No deaths occurred in this group. We also identified 3 premature neonates with invasive GAS disease unrelated to cases in adults; 1 infection was nosocomially acquired.
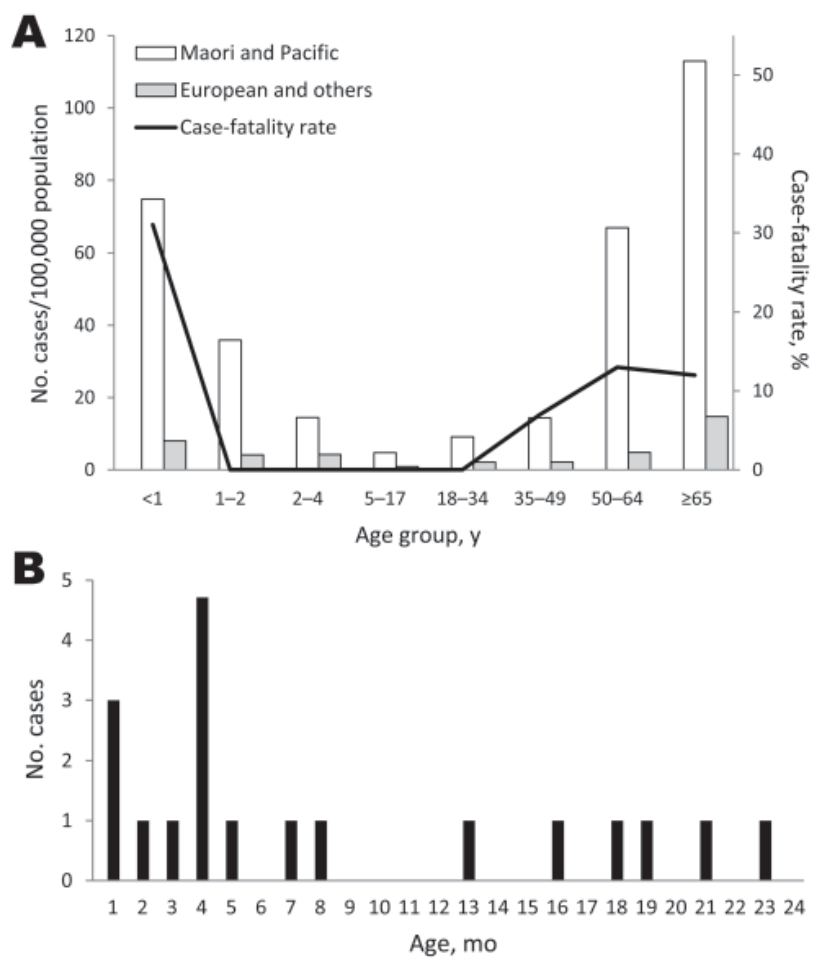

Figure 1. A) Annual incidence rates for invasive group $A$ streptococcal (GAS) disease, Auckland, New Zealand, 20052006. The black line indicates age-specific case-fatality rates for combined ethnicities. B) Number of invasive GAS cases among infants $\leq 24$ months of age.

\section{Risk Factors}

Of the 223 patients for whom data were available, 58 $(26 \%)$ had no underlying condition or other risk factor, 114 $(51 \%)$ had 1 or 2 risk factors, and $64(28 \%)$ had $\geq 3$ risk factors. In the $\geq 15$-years age group, 67 (35\%) had heart disease, 60 (32\% [23 Maori, 25 Pacific Islanders]) had diabetes, and $21 \%$ had either renal disease (39 persons) or lung disease (40 persons). Cigarette smoking was the most common nondisease-related risk factor (56 [30\%] of 189 persons $\geq 15$ years of age).

\section{Microbiological Analysis and Potential Vaccine-Preventable Disease}

GAS was most frequently isolated from peripheral blood cultures (184 [82\%]). Other sources were surgical specimen (37 isolates), tissue specimen (18), joint aspirate (16), pus aspirate (12), catheter blood culture (6), peritoneal aspirate (2), cerebrospinal fluid (2), and postmortem blood (3).

Of the 225 cases, 205 (91\%) GAS isolates were available for emm typing (Figure 2). Seventy (34\%) of 205 cases had an emm type that was contained in the 26-valent vaccine. The proposed 26 -valent vaccine could prevent 
Table 1. Population-based incidence of invasive group A streptococcal disease, by age, Auckland, New Zealand, 2005-2006*

\begin{tabular}{|c|c|c|c|c|c|c|c|c|c|c|}
\hline \multirow[b]{3}{*}{ Population } & \multicolumn{10}{|c|}{ Age group, y } \\
\hline & \multicolumn{2}{|c|}{$<1$} & \multicolumn{2}{|c|}{$<15$} & \multicolumn{2}{|c|}{$\leq 50$} & \multicolumn{2}{|c|}{$\geq 65$} & \multicolumn{2}{|c|}{ All ages } \\
\hline & No. & Rate & No. & Rate & No. & Rate & No. & Rate & No. & Rate \\
\hline Maori and Pacific Islander & 11 & 20.3 & 27 & 13.0 & 74 & 80.1 & 30 & 113.0 & 139 & 20.4 \\
\hline Maori & 8 & 40.9 & 14 & 14.1 & 33 & 82.5 & 15 & 146.8 & 69 & 21.6 \\
\hline Pacific Islander & 3 & 16.4 & 13 & 12.0 & 41 & 78.2 & 15 & 91.8 & 70 & 19.3 \\
\hline Other & 2 & 4.1 & 9 & 2.4 & 53 & 8.9 & 36 & 15.0 & 84 & 5.3 \\
\hline Total & 13 & 33.0 & 36 & 6.1 & 127 & 18.4 & 66 & 24.4 & 225 & 8.1 \\
\hline $\begin{array}{l}{ }^{*} \text { Rate/ } 100,000 \text { population. Ta } \\
\text { ethnicity on risk in different ag } \\
11.32 \text { ) and for Pacific Islande } \\
0.96-1.74) \text {. }\end{array}$ & & opul & & $f a$ & & $\bmod$ & $\mathrm{dn}$ & nce & $\begin{array}{l}\text { rence i } \\
\text { e inter } \\
\text { s } 1.29\end{array}$ & $\begin{array}{l}\text { effect } \\
\text { I] } 5.10- \\
0 \mathrm{Cl}\end{array}$ \\
\hline
\end{tabular}

$30 \%$ of GAS invasive cases in children $<5$ years of age and $15 \%$ of cases in persons $\geq 65$ years of age (Table 4 ).

Of the 225 isolates, $1(0.4 \%)$ was resistant to erythromycin and $1(0.4 \%)$ had intermediate sensitivity to erythromycin. Three (1.3\%) were resistant to clindamycin.

\section{Disease Severity}

Hospitalization was required for 222 patients ( 3 deaths occurred in the community). Length of stay was $>10$ days for 105 (47\%); mean length of stay was 15.9 days (range 1-153 days). Thirty-eight (17\%) required ICU admission (mean length of stay 4.5 days; range $1-9$ days); maximum length of stay was 19 days. Nosocomial infection was responsible for $12(5 \%)$ of the 225 cases. Seventy-five $(33 \%)$ patients required at least 1 surgical procedure, predominantly drainage, débridement, or washouts. One patient (2 years of age) with STSS required intravenous immunoglobulin.

\section{Discussion}

Our New Zealand study is population based and prospective. The overall annual incidence rate for greater Auckland of 8.1 cases per 100,000 persons per year is more than double or triple the rate of earlier reports elsewhere in the industrialized world. Annualized rates reported from

\begin{tabular}{lc}
\hline $\begin{array}{l}\text { Table 2. Invasive GAS infection and relation with socioeconomic } \\
\text { status, Auckland, New Zealand, 2005-2006* }\end{array}$ \\
$\begin{array}{lc}\text { New Zealand Deprivation } & \text { No. (\%) confirmed invasive GAS } \\
\text { Infex 2006† }\end{array}$ \\
\hline 10 & $63(32)$ \\
9 & $33(17)$ \\
8 & $23(12)$ \\
7 & $23(12)$ \\
6 & $10(5)$ \\
5 & $10(5)$ \\
4 & $6(3)$ \\
3 & $10(5)$ \\
2 & $15(8)$ \\
1 & $5(3)$ \\
\hline *Based on the 198 case-patients for whom socioeconomic status \\
information was available. GAS, group A streptococcal. \\
†New Zealand Ministry of Health, www.moh.govt.nz. 10, most deprived \\
area; 1, least deprived area.
\end{tabular}

other industrialized countries were 3.5 per 100,000 in 2007 in the United States (2); 1.5 in Ontario, Canada; and 3.1 in the Netherlands $(1,23)$.

This study was conducted in metropolitan Auckland, where studies are ongoing to assess GAS disease, including endemic ARF $(11,12,24)$, APSGN (http://dnmeds.otago. ac.nz/departments/womens/paediatrics/research/nzpsu/ pdf/2008_report.pdf), and streptococcal pharyngitis (25) with associated $\mathrm{emm}$ typing. Our study was conducted in close association with ongoing active surveillance for ARF and its associated emm types (26) and APSGN surveillance. Our laboratory-based surveillance was supported by discharge data evaluation, chart review, and coroner surveillance, which minimized underestimation of STSS and NF. Approximately 50-70 new ARF cases (90\% in persons $<20$ years) occur each year in this population $(12,24)$ and a similar number of APSGN. The incidence of streptococcal pharyngitis has been carefully determined in a randomized controlled trial for ARF control at $\approx 60$ cases per 100 child-years during a 4-year period in a population of $\approx 12,000$ persons $5-19$ years of age (11). This rate is considerably higher than that documented recently from Fiji (14.7/100 child-years) (27). Serotypes in ARF cases in our study were diverse (emm 58, 74, 75, 76, 92, 99, and 53), mirroring an earlier report (emm 53 and 58 associated with ARF) (28).

The annualized rate for Maori and Pacific Islanders $<1$ year of age $(75 / 100,000)$ was similar to rates reported from Kenya (29) and greater than the rate more recently reported from Fiji $(44.9 / 100,000)$ (27) from prospective studies. Nearly $50 \%$ of cases occurred in the lowest SES quintile of Auckland. Indigenous Maori and Pacific Islanders are overrepresented in lower SES areas of Auckland. Ethnically disparate rates for invasive GAS parallel these findings, with overrepresentation of these groups. The New Zealand Deprivation Index uses multiple parameters, including housing, income, and education. In addition, access to health care may be deficient $(30,31)$ and perhaps health knowledge as well. The role of crowded housing in the population in our study has been recently documented for epidemic meningococcal disease (32) and may have a 
Invasive Group A Streptococcal Infection

Table 3. Clinical syndromes and CFRs for 225 patients with invasive GAS disease, Auckland, New Zealand, 2005-2006*

\begin{tabular}{|c|c|c|c|c|c|c|}
\hline \multirow[b]{3}{*}{ Diagnosis $†$} & \multicolumn{4}{|c|}{ Age group, y } & \multirow{3}{*}{$\begin{array}{c}\text { All ages, no. (\%), } \neq \\
N=225\end{array}$} & \multirow[b]{3}{*}{$\mathrm{p}$ values } \\
\hline & \multicolumn{2}{|c|}{$0-14, n=36$} & \multicolumn{2}{|c|}{$\geq 15, n=189$} & & \\
\hline & No. & CFR & No. & CFR & & \\
\hline Skin and soft tissue infectiont & 11 & 0 & 86 & 8 & $97(43)$ & 0.14 \\
\hline Bacteremia only & 7 & 38 & 31 & 19 & $38(16)$ & 0.63 \\
\hline STSS\#** & 6 & $67 \dagger \dagger$ & 24 & 54 & $30(13)$ & 0.59 \\
\hline Bone infection & 6 & 0 & 20 & 0 & $26(12)$ & 0.39 \\
\hline Pneumonia and other respiratory infection & 12 & 13 & 12 & 0 & $24(11)$ & 0.0001 \\
\hline Necrotizing fasciitis ${ }^{\star \star}$ & 1 & 0 & 19 & 15 & $20(9)$ & 0.21 \\
\hline Pelvic infection/peripartum $\ddagger \ddagger$ & 0 & 0 & 12 & 0 & $12(5)$ & \\
\hline
\end{tabular}

${ }^{*}$ CFR, case-fatality rate; GAS, group A streptococcal; STSS, streptococcal toxic shock syndrome.

†Patients may have had $>1$ diagnosis, with the exception of bacteremia without a source. Other conditions (not shown) included 4 upper airway infections

6 ear/nose/throat infections, 5 central nervous system infections, 4 cases of peritonitis, 3 urinary tract infections, and 2 hemodialysis vascular access infections. No deaths occurred in this group.

‡Overall CFR 10\% (22/225).

§p value calculated by using Fisher exact test, a test of difference between age groups.

TIncludes cellulitis $(n=79)$, cutaneous abscess, boil, lymphadenitis, myositis, bursitis, infected burn, infected scabies, and infected ulcer with evidence of documented bacteremia.

\#STSS confirmed and probable $(\mathrm{n}=3)$

**Five patients had STSS and NF; $1 / 5$ died (20\% CFR)

††Three of 6 were community deaths in infants $<1$ y of age.

捛cludes pregnancy-related $(n=6)$ endometritis and infected products, urinary tract infection/chorioamnionitis, and wound problems

more substantial role for GAS disease, which is considered to be even more contagious (33). The high likelihood of an associated risk factor in the adult population, such as a chronic disease or another association, has been reported many times $(1,2,27,34)$.

Skin infections have been documented as a major cause of illness in Auckland (35). More recently, New Zealand surveillance data (24) reported highly discrepant hospitalization rates for serious skin disease: Maori and Pacific Islanders $<15$ years of age are more likely to be hospitalized (unadjusted rate ratios 2.77 [95\% CI 2.662.88] and 4.47 [95\% CI 4.27-4.68], respectively) than are New Zealand European children 0-14 years of age. These data also reflected more hospitalizations for persons living in the most deprived quintile (24), which most likely is related to poor access to primary care and perhaps health knowledge. High population-based rates of invasive disease caused by methicillin-sensitive $S$. aureus, mostly bone and joint disease, also have been documented (36).
The overall CFR from our study (10\%), with a high CFR for STSS (63\%), mirrors other studies in the industrialized world (2). This CFR suggests good access to hospital care and efficiently delivered secondary and tertiary care, including ICU admission. A recently reported CFR (28\%) from Fiji suggests otherwise from the developing world (27).

We included in our study all 3 infants who died in the community and from whom GAS was cultured (37). GAS is a rare finding from postmortem specimens (J. Zucollo, pers. comm.). In all 3 cases, only gram-positive organisms were isolated (1 solely group A streptococcus from blood and cerebrospinal fluid). Studies in which careful precautions have been taken to reduce contamination show that approximately two thirds of blood cultures yield negative results, 2 in 9 yield 1 isolate, and 1 in 9 show mixed growth. GAS infection as the sole cause of death was less certain in 2 cases in our study in which $>1$ potentially diseasecausing species was cultured. We characterized the 3 infant deaths as STSS according to Davies et al. (1), a definition

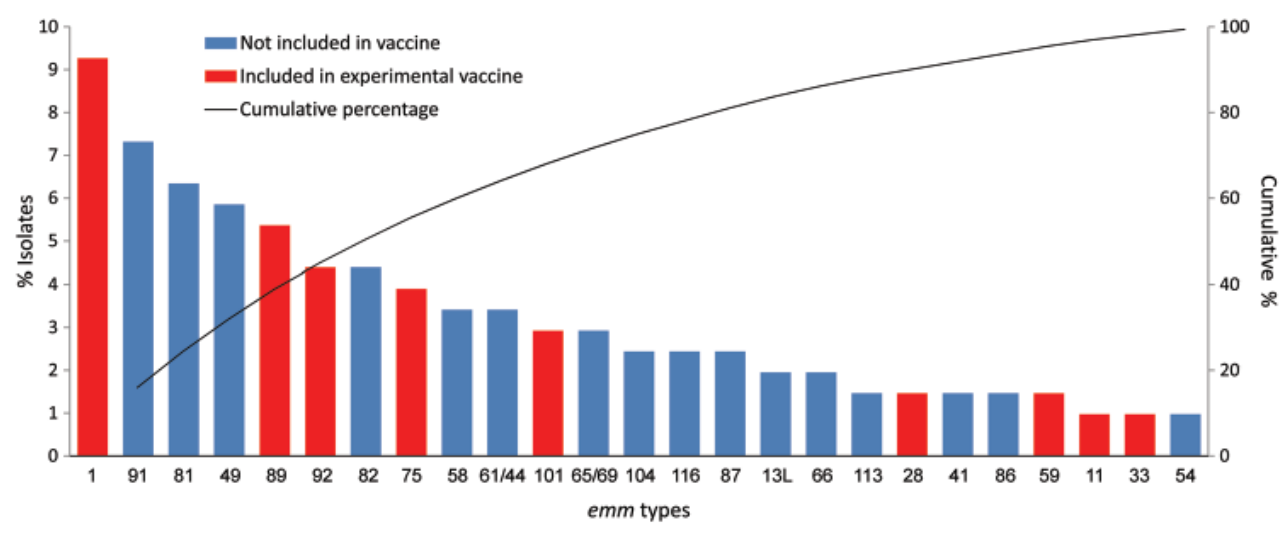

Figure 2. The 25 most common emm types as a proportion of all isolates. The remaining emm types were as follows: $100,107,25,53,56,22,18$, $103,105,106,108,112,123$, 4, 51, 55, 70, 73, 77/27L, DRX4, ST6030, STN5554, 109, 110, 12, 52, 77, 88, 97, ST4119, ST4547, and 76 . 
Table 4. Invasive GAS disease and fatalities potentially prevented by vaccination of infants and elderly persons with a proposed 26valent vaccine, Auckland, New Zealand, 2005-2006*

\begin{tabular}{|c|c|c|c|c|c|c|}
\hline $\begin{array}{l}\text { Age group, y } \\
\text { (no. emm typed) }\end{array}$ & $\begin{array}{l}\text { Assumed } \\
\text { vaccine } \\
\text { efficacy, \% }\end{array}$ & $\begin{array}{l}\text { Assumed } \\
\text { vaccine } \\
\text { coverage, \% }\end{array}$ & $\begin{array}{l}\text { No. }(\%) \text { persons with GAS } \\
\text { disease from emm types in } \\
\text { the } 26 \text {-valent vaccine } \dagger\end{array}$ & $\begin{array}{l}\text { GAS-related deaths } \\
\text { from emm type in the } \\
26 \text {-valent vaccine }+, \%\end{array}$ & $\begin{array}{c}\text { Potential GAS } \\
\text { disease } \\
\text { prevented \%‡ }\end{array}$ & $\begin{array}{l}\text { Potential GAS- } \\
\text { related deaths } \\
\text { prevented, \%§ }\end{array}$ \\
\hline$<<5(25)$ & $\geq 84$ & $80 \pi$ & $11(44)$ & $1 \#$ & 29.6 & 0.67 \\
\hline$\geq 65(59)$ & 84 & 60 ** & $18(30.5)$ & $14(1 / 7)$ & 15 & 7.1 \\
\hline
\end{tabular}

*GAS, group A streptococcal.

†Among patients with typed isolates.

$\ddagger$ Percentage of assumed vaccine efficacy $\times$ percentage of assumed vaccine coverage $\times$ persons with GAS disease from 26 -valent emm types (based on O'Loughlin et al. [2]).

§Percentage of assumed vaccine efficacy $\times$ percentage of assumed vaccine coverage $\times$ persons with GAS disease from 26 -valent emm types $\times$ percentage of GAS-related deaths associated with a 26-valent emm type.

TCraig et al. (24).

\#Of the 4 children $<5$ years of age, 2 had an emm typed isolate. Neither of these types is in the proposed vaccine. These are very small numbers. **New Zealand Ministry of Health Immunisation Handbook (www.moh.govt.nz).

that produces higher rates of STSS and a higher CFR in children than in other reports. We look forward to further investigations in this area.

Current health strategies for preventing illness and death from invasive GAS infections are limited. The rate of nosocomial infection in our study was low. The high rates in postpartum women and in infants require further investigation. We were unaware of any links between cases in our series. In New Zealand, index cases of invasive GAS disease are not investigated by public health authorities (38). Primordial strategies, such as of the provision of lesscrowded housing (32) and hand-washing education, need further consideration (39).

The currently available vaccine most advanced in clinical trials (14) comprises $26 \mathrm{emm}$ types representing population-based, practice-based, and historical assessments from the United States (14). Its applicability to the population in our study might be less than ideal. Thirtyfour percent of disease was caused by emm types in the proposed 26-valent vaccine. Data are accruing from other sites $(79 \% \mathrm{emm}$ coverage with the 26 -valent vaccine in the United States, $69 \%$ in Europe, and $40 \%$ in Fiji) $(4,14,27)$. Our data can contribute to a recent global estimate suggesting the current formulation of an experimental multivalent GAS vaccine may not be ideal in areas of most need (40). The effectiveness estimate in our study (Table 4) suggests that fewer than one third of invasive GAS cases in children $<5$ years of age and perhaps $15 \%$ of cases in persons $\geq 65$ years of age could be prevented. This finding is of particular concern in a New Zealand population where other GAS-associated diseases cause a substantial amount of illness and death.

The rates in our study, driven largely by high rates in indigenous Maori and Pacific Islanders, are higher than those previously reported from industrialized countries and similar to reports from Fiji and Kenya. The rates suggest a need for more investigation and planned interventions in populations at highest risk. Our study also supports the role of GAS as a pathogen for invasive disease, particularly because of its effect on all age groups.

\section{Acknowledgment}

We thank the microbiology laboratories for sharing data.

Dr Safar is an advanced trainee in emergency medicine at Auckland City Hospital, Auckland, New Zealand. His primary research interests include severe sepsis and critically ill patients, trauma, and toxicology.

\section{References}

1. Davies HD, McGeer A, Schwartz B, Green K, Cann D, Simor AE, et al. Invasive group A streptococcal infections in Ontario, Canada. N Engl J Med. 1996;335:547-54. doi:10.1056/ NEJM199608223350803

2. O'Loughlin RE, Roberson A, Cieslak PR, Lynfield R, Gershman K, Craig A, et al. The epidemiology of invasive group A streptococcal infection and potential vaccine implications: United States, 20002004. Clin Infect Dis. 2007;45:853-62. doi:10.1086/521264

3. Zurawski CA, Bardsley M, Beall B, Elliott JA, Facklam R, Schwartz $\mathrm{B}$, et al. Invasive group A streptococcal disease in metropolitan Atlanta: a population-based assessment. Clin Infect Dis. 1998;27:1507. doi:10.1086/514632

4. Luca-Harari B, Darenberg J, Neal S, Siljander T, Strakova L, Tanna A, et al. Clinical and microbiological characteristics of severe Streptococcus pyogenes disease in Europe. J Clin Microbiol. 2009;47:1155-65. doi:10.1128/JCM.02155-08

5. World Health Organization. The current evidence for the burden of group A streptococcal diseases. Geneva: The Organization; 2005. p. 60 .

6. Jaine R, Baker M, Venugopal K. Epidemiology of acute rheumatic fever in New Zealand 1996-2005. J Paediatr Child Health. 2008;44:564-71. doi:10.1111/j.1440-1754.2008.01384.x

7. Kerdemelidis M, Lennon DR, Arroll B, Peat B, Jarman J. The primary prevention of rheumatic fever. J Paediatr Child Health. 2010;46:534-48. doi:10.1111/j.1440-1754.2010.01854.x

8. Harnden A, Lennon D. Serious suppurative group A streptococcal infections in previously well children. Pediatr Infect Dis J. 1988;7:714-8. doi:10.1097/00006454-198810000-00010

9. Atatoa-Carr P, Bell A, Lennon DR. Acute rheumatic fever in the Waikato District Health Board region of New Zealand: 1998-2004. N Z Med J. 2008;121:96-105.

10. Lennon D, Martin D, Wong E, Taylor LR. Longitudinal study of poststreptococcal disease in Auckland; rheumatic fever, glomerulonephritis, epidemiology and M typing 1981-86. N Z Med J. 1988;101:396-8.

11. Lennon D, Stewart J, Farrell E, Palmer A, Mason H. School-based prevention of acute rheumatic fever: a group randomized trial in New Zealand. Pediatr Infect Dis J. 2009;28:787-94. doi:10.1097/ INF.0b013e3181a282be 
12. Spinetto H, Lennon D, Horsburgh M. Rheumatic fever recurrence prevention: a nurse-led programme of 28 days penicillin in an area of high endemnicity. J Paediatr Child Health. 2011. In press

13. Bisno AL, Rubin FA, Cleary PP, Dale JB, National Institute of Allergy and Infectious Diseases. Prospects for a group A streptococcal vaccine: rationale, feasibility, and obstacles - report of a National Institute of Allergy and Infectious Diseases workshop. Clin Infect Dis. 2005;41:1150-6. doi:10.1086/444505

14. McNeil SA, Halperin SA, Langley JM, Smith B, Warren A, Sharrat GP, et al. Safety and immunogenicity of 26-valent group A streptococcus vaccine in healthy adult volunteers. Clin Infect Dis. 2005;41:1114-22. doi:10.1086/444458

15. Voss L, Lennon D, Okesene-Gafa K, Ameratunga S, Martin D. Invasive pneumococcal disease in a pediatric population, Auckland, New Zealand. Pediatr Infect Dis J. 1994;13:873-8. doi:10.1097/00006454-199410000-00005

16. Lennon D, Voss L, Sinclair J, Heffernan H. An outbreak of meningococcal disease in Auckland, New Zealand. Pediatr Infect Dis J. 1989;8:11-5. doi:10.1097/00006454-198901000-00004

17. Jefferies C, Lennon D, Stewart J, Martin D. Meningococcal disease in Auckland, July 1992-June 1994. N Z Med J. 1999;112:115-7.

18. Lennon D, Walker W, Voss L, Gillies M, Martin D, Ashton T, et al. The case for Haemophilus influenzae type b vaccination in New Zealand. Commun Dis N Z. 1992;92:89-96.

19. Defining the group A streptococcal toxic shock syndrome. Rationale and consensus definition. The Working Group on Severe Streptococcal Infections. JAMA. 1993;269:390-1. doi:10.1001/ jama.269.3.390

20. Chuang I, Van Beneden C, Beall B, Schuchat A. Populationbased surveillance for postpartum invasive group a streptococcus infections, 1995-2000. Clin Infect Dis. 2002;35:665-70. doi:10.1086/342062

21. Beall B, Facklam R, Thompson T. Sequencing emm-specific PCR products for routine and accurate typing of group A streptococci. J Clin Microbiol. 1996;34:953-8.

22. Clinical and Laboratory Standards Institute. Performance standards for antimicrobial susceptibility testing. 20th informational supplement. Wayne (PA): The Institute; 2010

23. Vlaminckx BJ, van Pelt W, Schouls LM, van Silfhout A, Mascini EM, Elzenaar CP, et al. Long-term surveillance of invasive group A streptococcal disease in the Netherlands, 1994-2003. Clin Microbiol Infect. 2005;11:226-31. doi:10.1111/j.1469-0691.2004.01068.x

24. Craig E, Jackson C, Han DY, NZCYES Steering Committee, et al. Monitoring the health of New Zealand children and young people: indicator handbook. Auckland (New Zealand): Paediatric Society of New Zealand, New Zealand Child and Youth Epidemiology Service; 2007. p. 218

25. Lennon D, Kerdemelidis M, Arroll B. Meta-analysis of trials of streptococcal throat treatment programs to prevent rheumatic fever. Pediatr Infect Dis J. 2009;28:e259-64. doi:10.1097/ INF.0b013e3181a8e12a

26. O'Brien B, Lennon D, Thornley C. Group A streptococcal throat carriage and pharyngitis in household contacts of acute rheumatic fever cases in Auckland [abstract]. In: Paediatric Society of New Zealand. Annual Scientific Conference (abstracts), 2009 Nov 24-27. Hamilton and Wellington (New Zealand): Paediatric Society of New Zealand; 2009.

27. Steer AC, Jenney A, Kado J, Good MF, Batzloff M, Waqatakirewa L, et al. Prospective surveillance of invasive group A streptococcal disease, Fiji, 2005-2007. Emerg Infect Dis. 2009;15:216-22. doi:10.3201/eid1502.080558
28. Martin DR, Voss LM, Walker SJ, Lennon D. Acute rheumatic fever in Auckland, New Zealand: spectrum of associated group A streptococci different from expected. Pediatr Infect Dis J. 1994;13:264-9. doi:10.1097/00006454-199404000-00004

29. Berkley JA, Lowe BS, Mwangi I, Williams T, Bauni E, Mwarumba $\mathrm{S}$, et al. Bacteremia among children admitted to a rural hospital in Kenya. N Engl J Med. 2005;352:39-47. doi:10.1056/NEJMoa040275

30. New Zealand Ministry of Health. Tupu Ola Moui. Pacific health chart book 2004. Wellington (New Zealand): The Ministry; 2004. p. $1-197$.

31. New Zealand Ministry of Health. Tatau Kahukura: Maori health chart book 2006. Wellington (New Zealand): The Ministry; 2006. p. $1-79$.

32. Baker M, McNicholas A, Garrett N, Jones N, Stewart J, Koberstein $\mathrm{V}$, et al. Household crowding a major risk factor for epidemic meningococcal disease in Auckland children. Pediatr Infect Dis J. 2000;19:983-90. doi:10.1097/00006454-200010000-00009

33. Richardson M, Elliman D, Maguire H, Simpson J, Nicoll A. Evidence base of incubation periods, periods of infectiousness and exclusion policies for the control of communicable diseases in schools and preschools. Pediatr Infect Dis J. 2001;20:380-91. Erratum in: Pediatr Infect Dis J. 20011;20:653. doi:10.1097/00006454200104000-00004

34. Lamagni TL, Neal S, Keshishian C, Alhaddad N, George R, Duckworth G, et al. Severe Streptococcus pyogenes infections, United Kingdom, 2003-2004. Emerg Infect Dis. 2008;14:202-9. doi:10.3201/eid1402.070888

35. Tiu A, Martin R, Vanniasingham P, MacCormick AD, Hill AG. Necrotizing fasciitis: analysis of 48 cases in South Auckland, New Zealand. ANZ J Surg. 2005;75:32-4. doi:10.1111/j.14452197.2005.03289.x

36. Lennon D, Voss L, Ameratunga S. Invasive bacterial disease in childhood [abstract]. In: Abstracts of the 33rd Interscience Conference on Antimicrobial Agents and Chemotherapy; New Orleans, Louisiana, October 17-20, 1993. Abstract 370. Washington: American Society for Microbiology; 1993.

37. Morris JA, Harrison LM, Partridge SM. Postmortem bacteriology: a re-evaluation. J Clin Pathol. 2006;59:1-9. doi:10.1136/ jcp.2005.028183

38. Prevention of invasive group A streptococcal disease among household contacts of case patients and among postpartum and postsurgical patients: recommendations from the Centers for Disease Control and Prevention. Clin Infect Dis. 2002;35:950-9. Erratum in: Clin Infect Dis. 2003;36:243. doi:10.1086/342692

39. Hennessy TW, Ritter T, Holman RC, Bruden DL, Yorita KL, Bulkow $\mathrm{L}$, et al. The relationship between in-home water service and the risk of respiratory tract, skin, and gastrointestinal tract infections among rural Alaska natives. Am J Public Health. 2008;98:2072-8. doi:10.2105/AJPH.2007.115618

40. Steer AC, Law I, Matatolu L, Beall BW, Carapetis JR. Global emm type distribution of group A streptococci: systematic review and implications for vaccine development. Lancet Infect Dis. 2009;9:6116. doi:10.1016/S1473-3099(09)70178-1

Address for correspondence: Diana Lennon, Community Paediatrics, The University of Auckland, Private Bag 92019, Auckland, New Zealand; email: d.lennon@auckland.ac.nz

\section{Search past issues of EID at www.calc.gov/eid}

